\title{
FLIGHT OF THE EYE GNAT, HIPPELATES PALLIPES (DIPTERA: CHLOROPIDAE): CORRELATION WITH TEMPERATURE, LIGHT, MOISTURE AND WIND VELOCITY ${ }^{1}$
}

\author{
By Reid R. Gerhardt and R. G. Axtel1 ${ }^{2}$
}

\begin{abstract}
The flight activity, based on collections from humans, of Hippelates pallipes (Loew) eye gnats was measured under varying field conditions. Thresholds for flight were $18^{\circ} \mathrm{C}, 5.38$ milliphots ( $5 \mathrm{ft}-\mathrm{c}$ ) of light, and wind speed below $60-70 \mathrm{~m} / \mathrm{min}$. No gnats were captured at a vapor pressure deficit of $0.0 \mathrm{~mm} \mathrm{Hg}$. Graphs are presented for flight activity at various values of temperature, light, VPD, and wind speed. Comparisons are made between the responses of $H$. pusio and $H$. pallipes to temperature, light, VPD, and wind speed.
\end{abstract}

Hippelates pallipes (Loew) is an annoying pest of man and animals in North Carolina. Like $H$. pusio Loew, it is attracted to body secretions and wounds. $H$. pallipes has not been directly implicated in the transmission of any disease, but the similarity of its biology to that of other Hippelates makes it suspect. $H$. pusio has been implicated as a possible vector in the spread of conjunctivitis, anaplasmosis and bovine mastitis (Dow \& Hines 1957, Roberts 1968, Sanders 1940). H. flavipes Loew has been implicated in the transmission of yaws in Jamaica by Kumm \& Turner (1936), who incorrectly used the name $H$. pallipes according to Sabrosky (1951). H. flavipes has been incriminated in the spread of staphylococcal skin infections in Panama (Taplin et al. 1967). H. flavipes, $H$. currani Aldrich and $H$. peruanus Becker have been associated with staphylococcal skin infections in Trinidadian children (Bassett 1970).

Generally $H$. pallipes is less abundant than $H$. pusio in North Carolina, but on some occasions it is the dominant Hippelates species annoying man (Axtell \& Edwards 1970). Other investigators in the southeastern United States either have not reported any data on $H$. pallipes (Jay 1962) or have reported only occasional captures (Bigham 1941, Dow \& Hutson 1958). In Wisconsin, Hummadi \& DeFoliart (1967) reported H. pallipes associated with various domestic and wild animals but did not collect from humans. Womeldorf \& Mortenson (1963) collected 6 specimens in Cali-

${ }^{1}$ This research was supported in part by training grant ES00069 from the National Institute of Environmental Health Sciences. Paper No. 3899 of the Journal Series of the North Carolina State University of the Agricultural Experiment Station.

${ }^{2}$ Research Associate and Professor, respectively, Department of Entomology, North Carolina State University, Raleigh, N. C. 27607 , U.S.A. fornia. The low numbers of $H$. pallipes reported may be a reflection of the collection methods in some cases. Axtell \& Edwards (1970) found that the baited traps designed to capture $H$. pusio were poor collectors of $H$. pallipes.

The factors determining the flight activity of $H$. pusio have been published (Gerhardt \& Axtell 1972) but not those for $H$. pallipes. The thresholds of flight for $\mathrm{H}$. pusio were determined to be $17^{\circ} \mathrm{C}$, $0.25 \mathrm{Hg}$ vapor pressure deficit (VPD), 5.38 milliphots (5 ft-c) of light and wind speed below 67 $\mathrm{m} / \mathrm{min}$. Data on other species of Hippelates are fragmentary. In the laboratory, H. collusor (Townsend) was shown to have varying flight activity when the wave length of light was changed while the light intensity was kept constant (Dorner \& Mulla 1961). The flight activity of $H$. collusor ceased at wind speeds in excess of $53.6 \mathrm{~m} / \mathrm{min}$. in a laboratory chamber. $H$. collusor preferred low relative humidity at low temperatures and high relative humidity at high temperatures under laboratory conditions (Dorner \& Mulla 1962). The average number of $H$. flavipes observed in the field was reduced $82 \%$ when the wind increased from $0-91 \mathrm{~m} / \mathrm{min}$. to $92-213 \mathrm{~m} / \mathrm{min}$. No $H$. flavipes were caught at wind speeds over $213 \mathrm{~m} / \mathrm{min}$. (Kumm 1935).

The objectives of this investigation were to determine how the physical environmental factors of temperature, light, atmospheric moisture, and wind influence the flight activity of $H$. pallipes when responding to human bait; specifically, (1) to determine what environmental conditions must exist in the field before $H$. pallipes will actively seek man, and (2) to determine how the changes in flight activity that have been observed in the course of a day are correlated with the naturally occurring changes in the physical environment. In addition, comparisons were made between the responses of $H$. pusio and $H$. pallipes to human bait.

\section{MATERIALS AND METHODS}

The methods and equipment were the same as used in the previous study on $H$. pusio (Gerhardt \& Axtell 1972). Field temperature measurements were made with a YSI ${ }^{\circledR}$ Model 47 Scanning Tele- 
Thermometer ${ }^{3}$ and recorded on a YSI Model 80 Laboratory Recorder. The heat sensitive elements were YSI $\$ 401$ thermistor probes. The probes were placed at 0.1 and $2 \mathrm{~m}$ above the ground in an open sunlit area and in an adjacent shaded area. All temperatures were recorded in degrees Celsius. Light was measured and recorded in the field with an automatic recording photometer (Berry \& Raney 1968). Two photo-sensitive cells were placed $2 \mathrm{~m}$ above the ground, one in the open sunlight and the other in the shaded area. Recording was continuous and in foot candles. Atmospheric moisture was determined by taking wet and dry bulb temperatures with a Model 566-2 Bendix Psychron ${ }^{\circledR 4}$. Wet and dry bulb temperatures were taken immediately after each gnat collection at 0.1 and $2 \mathrm{~m}$ above the ground. Wind speed was measured with a No. 3AM680 Slow Speed Anemometer $^{5}$ (range 6 to $300 \mathrm{~m} / \mathrm{min}$.) at the same time and place as the wet and dry bulb readings.

Two adult male humans were used as bait. The subjects sat on the ground across from each other and collected the gnats that came to them with a portable vacuum aspirator modified from a hand vacuum cleaner. The collection periods were 5 min. and made every $15 \mathrm{~min}$., with the subjects moving alternately between the sun and the shade. Collections usually started at 0530 EST and continued for 12-14 hr. The gnats were collected in vials and taken to the laboratory for counting and identification.

The analysis of the data for $H$. pallipes was made from collections on 8, 17, and 21 September 1970 at Whispering Pines, Moore County, N. C. and 15 July, 4 and 6 August 1971 at Raleigh, Wake County, N. C. The data were analyzed by multiple regression using a standard statistical program (Barr \& Goodnight 1971) on the IBM 360/165 computer in Research Triangle Park, N. C. The $\sqrt{\mathrm{x}+1}$ transformation was used on the dependent variable $(H$. pallipes) to stabilize the variance. TABLE 1 contains a list of the parameters used in the analysis and their symbols which will be used in the text.

All of the parameters (independent variables) shown in TABLE 1 were used in the regression analysis of the dependent variable. The final regression model was arrived at by reducing the

\footnotetext{
${ }^{3}$ Yellow Springs Instrument Co., Yellow Springs, Ohio 45387, U.S.A.

${ }^{4}$ Bendix Environmental Science Division, Baltimore, Md. 21204, U.S.A.

${ }^{5}$ G. M. Mfg. \& Instrument Corp., 2417 Third Avenue, New York, N. Y. 10451, U.S.A.
}

TABLE 1. List of parameters and corresponding symbols used in the multiple regression analysis.

\begin{tabular}{ll}
\multicolumn{1}{c}{ PARAMETER } & \multicolumn{1}{c}{ SYMBOL } \\
\hline Temperature & TEMP \\
Temperature $\times$ Temperature & STEMP \\
Temperature $\times$ Vapor Pressure Deficit & TVPD \\
Temperature $\times$ Wind $\times$ Vapor Pressure Deficit & TWV \\
Wind & WIND \\
Temperature $\times$ Wind & TW \\
Wind $\times$ Wind & SWIND \\
Wind $\times$ Vapor Pressure Deficit & WVPD \\
Vapor Pressure Deficit & VPD \\
Vapor Pressure Deficit $\times$ Vapor Pressure Deficit & SVPD \\
Reciprocal of the Vapor Pressure Deficit & RVPD \\
Relative Humidity & RH \\
Relative Humidity $\times$ Temperature & TRH \\
Relative Humidity $\times$ Wind & RHW \\
Temperature $\times$ Wind $\times$ Relative Humidity & TWRH \\
Temperature $\times$ Reciprocal of Vapor Pressure & \\
Deficit & TRVPD \\
Wind $\times$ Reciprocal of Vapor Pressure Deficit & WRVPD \\
Wind $\times$ Wind $\times$ RVPD & SWRVPD \\
Temperature $\times$ Wind $\times$ Wind & TSWIND \\
Light & LIGHT \\
Square Root of Light & ROOTLI \\
\hline
\end{tabular}

number of independent variables. This was accomplished by the step down method; i.e., variables with the most non-significant partial regression coefficients were rejected. The analysis was repeated several times, each time eliminating more non-significant variables, until only significant variables were left in the model.

This investigation was conducted entirely under natural field conditions using wild populations of gnats. This was done to eliminate the hazards of extrapolating laboratory behavior data, using inbred laboratory strains, to field conditions and wild populations.

\section{RESULTS}

TABLE 2 gives the results of the analysis. All of

TABLE 2. Significant parameters and results of statistical analysis.

\begin{tabular}{|c|c|c|c|}
\hline Parameter & $\begin{array}{l}\text { DEGREES } \\
\text { OF } \\
\text { FREEDOM }\end{array}$ & $\begin{array}{l}\text { REGRESSION } \\
\text { COEFFICIENT }\end{array}$ & F Statistic \\
\hline TEMP & 1 & 0.44185516 & $5.931 * *$ \\
\hline STEMP & 1 & -0.00604452 & $4.434 * *$ \\
\hline LIGHT & 1 & -0.00054866 & $21.434 * * *$ \\
\hline ROOTLI & 1 & 0.04900678 & $13.007 * * *$ \\
\hline VPD & 1 & 1.44259891 & $3.516^{*}$ \\
\hline SVPD & 1 & -1.40684844 & $3.405^{*}$ \\
\hline WIND & 1 & -0.02232375 & $26.197 * * *$ \\
\hline Error & 276 & & \\
\hline $\begin{array}{c}\text { Multiple } \\
* \mathrm{P}<0.1 \\
* * \mathrm{P}<0.0 \\
* * * \mathrm{P}<0.0\end{array}$ & relation & \multicolumn{2}{|c|}{ Coefficient $(\mathrm{R})^{2}=0.28295 * *$} \\
\hline
\end{tabular}


the 4 basic environmental factors (temperature, light, vapor pressure deficit and wind) contributed significantly to the change in the flight activity of $H$. pallipes. FIG. 1-4 illustrate the influences of these factors on the flight activity of the gnats in relation to human bait. When an environmental factor is not noted on a graph, the value of that factor was the average for the entire experiment (temperature $29.9^{\circ} \mathrm{C}$, light 3788 milliphots (3530 ft-c), VPD $10.3 \mathrm{~mm} \mathrm{Hg}$ and wind $23.6 \mathrm{~m} / \mathrm{min}$.).

Temperature. FIG. 1 shows the relationships between temperature and the flight activity of $H$. pallipes at selected vapor pressure deficits. Maximum activity was observed at $36^{\circ} \mathrm{C}$. Minimum temperatures for the initiation of flight were predicted to be between 18 and $19^{\circ} \mathrm{C}$ at the VPD values that are likely to occur at those temperatures in the morning. This range of temperatures for initiation of flight was consistent with field observations. The regression equation was extrapolated above the maximum temperature measured $\left(44^{\circ} \mathrm{C}\right)$ to determine that flight would theoretically cease between 49 and $56^{\circ} \mathrm{C}$.

Light. The response of $H$. pallipes to light at selected temperatures is shown in FIG. 2. Maximum activity was at about 2152 milliphots (2000 ft-c). Light levels below 1076 milliphots (1000 ft-c) cause a sharp decrease in activity. At higher light levels the activity also decreases, but not as rapidly as for low levels of light. Field observations indicate that flight activity ceases at about 5.38 milliphots $(5 \mathrm{ft}-\mathrm{c})$.

Vapor pressure deficit. Vapor pressure deficit was found to be a better predictor of gnat activity than relative humidity. As shown in FIG. 3, maximum activity occurred at about $12.5 \mathrm{~mm} \mathrm{Hg}$. At 0.0 $\mathrm{mm} \mathrm{Hg}$, no activity was observed in the field although the regression equation predicted some activity (except at $20^{\circ} \mathrm{C}$ ).

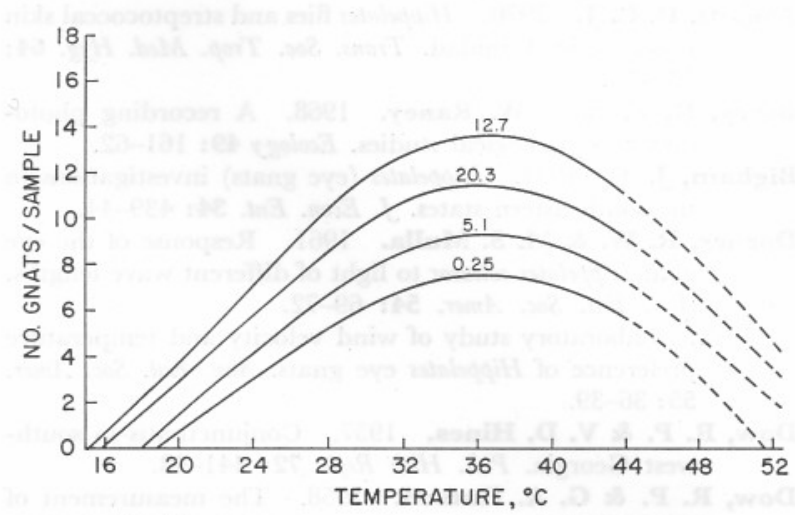

FIG. 1. Response to temperature at 4 vapor pressure deficits ( $\mathrm{mm} \mathrm{Hg}$ ).

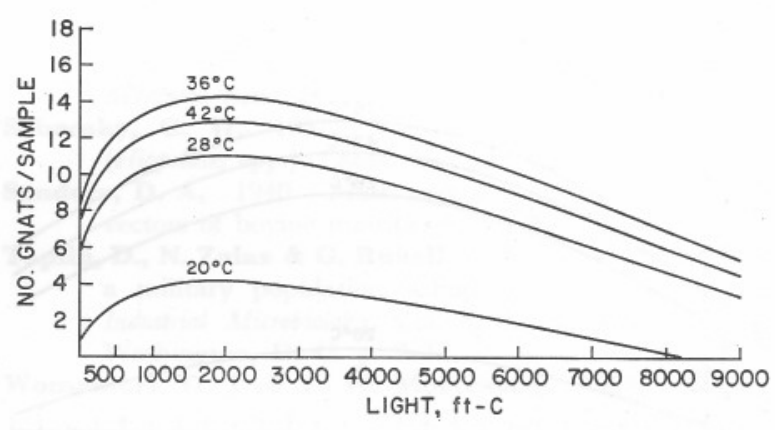

FIG. 2. Response to light at selected temperatures.

Wind. The predicted effect of wind on flight activity is shown in FIG. 4 . The wind often changed rapidly during the course of a single 5-min. collection period, thus making it the least reliable of the environmental measurements. Field observations confirmed, as predicted, that activity decreased as wind speed increased. Activity usually ceased at wind speeds between 60 and $70 \mathrm{~m} / \mathrm{min}$.

According to these data, certain physical environmental conditions must exist before $H$. pallipes is attracted to man. The temperature must be at least $18^{\circ} \mathrm{C}$, the light greater than 5.38 milliphots ( $5 \mathrm{ft}-\mathrm{c}$ ), and the wind less than $60-70 \mathrm{~m} / \mathrm{min}$. If the VPD is $0.0 \mathrm{~mm} \mathrm{Hg}$, there will be no flight activity. The flight activity can be predicted in relation to changes in the temperature, light, VPD, and wind speed.

\section{DISCUSSION}

H. pallipes responds to human bait in much the same manner as $H$. pusio (Gerhardt \& Axtell, 1972). The activity of both species is correlated with temperature, light, atmospheric moisture, and wind.

Temperature. The temperature is one of the primary factors limiting the flight of gnats in the morning during the summer months in North Carolina. If the other factors are equal and not limiting for flight, $H$. pallipes will commence activity earlier in the day than $H$. pusio. Low flight activity is associated with the cool temperatures of the early morning hours; activity was observed earlier in the warmer sunlit areas than in the cooler shaded areas. As the temperature increases the flight activity of both species also increases. When the temperature goes above $34^{\circ} \mathrm{C}$ for $H$. pusio and $36^{\circ} \mathrm{C}$ for $H$. pallipes, the flight activity decreases. These temperatures are commonly surpassed in the open sunlight in the early and mid-afternoon. Under these conditions, more flight activity is observed in the shaded areas where the temperature is more 


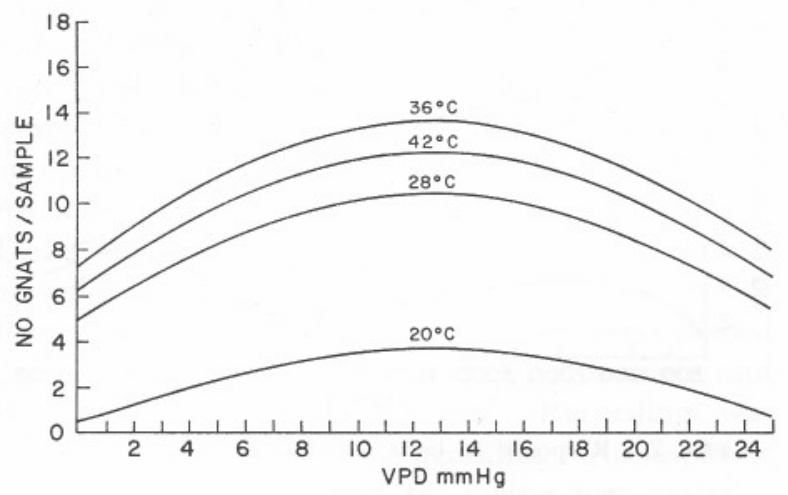

FIG. 3. Response to VPD at selected temperatures.

moderate. In the late afternoon and early evening the temperatures decrease and the difference in temperature between the sun and shade areas is less. As a result, there is little difference in flight activity between the sun and shade areas.

Light. The lowest light level at which we observed any gnat activity was 5.38 milliphots (5 ft-c). However, on most mornings during the gnat season in North Carolina, activity starts at a much higher level [ca 538-1076 milliphots (500$1000 \mathrm{ft}-\mathrm{c})]$ because the temperature and VPD are too low for flight. Maximum activity was predicted to be 2152 milliphots (2000 ft-c) for $H$. pallipes and 3228 milliphots (3000 ft-c) for $H$. pusio. Lower activity was correlated with the high light levels that occurred in the open sunlit areas. The light levels in the shaded areas were near the optimum for flight and this contributed to the increased activity in these areas in the afternoon. On cloudy or overcast days this difference was not as noticeable because the light in both places was at about the same level. The flight activity of $H$. pallipes was more adversely affected by high levels of light than that of $H$. pusio, which suggests that $H$. pallipes is more inclined to inhabit shade.

The light conditions that exist in the late afternoon and evening are ideal for high activity and this in part accounts for the high activity observed in both the sun and shade areas at that time of day.

Light is usually the environmental factor that causes flight activity to cease as the day ends. When both the temperature and VPD are within favorable ranges, activity ceases at 5.38 milliphots $(5 \mathrm{ft}-\mathrm{c})$.

$V P D$. VPD is the other environmental factor of primary importance in determining when activity starts in the morning for both species. If the VPD is $0.0 \mathrm{~mm} \mathrm{Hg}$ ( $100 \%$ saturation), there is no flight activity. As the air becomes unsaturated, a rapid

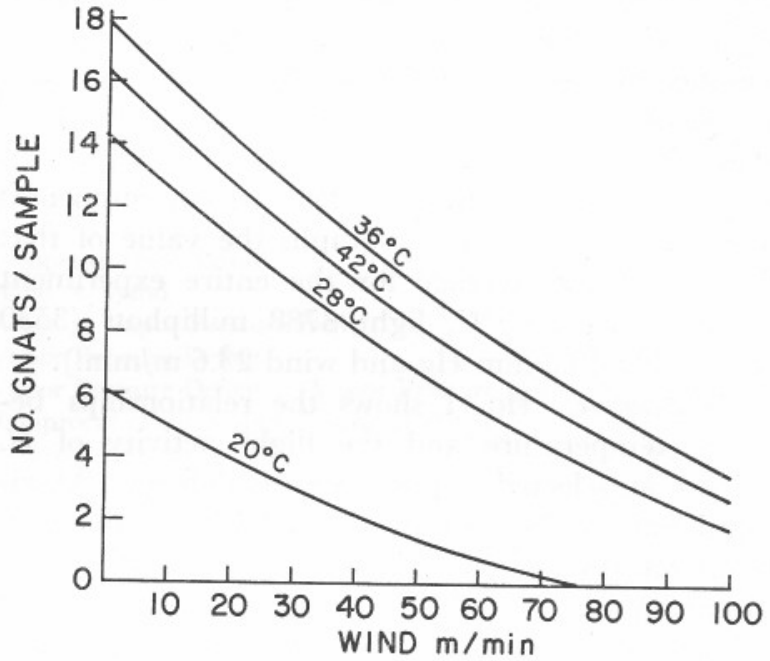

FIG. 4. Response to wind at selected temperatures.

rise in flight activity is correlated with increased VPD, up to about $3 \mathrm{~mm} \mathrm{Hg}$. For H. pusio, there is little change in activity above this level of VPD. $H$. pallipes, on the other hand, shows increased activity up to $12.5 \mathrm{~mm} \mathrm{Hg}$. Above that point there is a negative correlation between flight activity and VPD.

Wind. Both species exhibit maximum activity at low wind speeds. Any measurable amount of wind will reduce activity, and speeds above $60 \mathrm{~m} / \mathrm{min}$. reduce activity drastically. Wind speed has a greater adverse effect on the activity of $H$. pallipes than on $H$. pusio.

\section{LITERATURE CITED}

Axtell, R. C. \& T. D. Edwards. 1970. Seasonal populations of Hippelates gnats (Diptera: Chloropidae) in North Carolina. Ann. Ent. Soc. Amer. 63: 1049-53.

Barr, A. J. \& J. H. Goodnight. 1971. Statistical Analysis System. Student Supply Store, North Carolina State University, Raleigh.

Bassett, D. C. J. 1970. Hippelates flies and streptococcal skin infection in Trinidad. Trans. Soc. Trop. Med. Hyg. 64: $138-47$.

Berry, R. E. \& L. W. Raney. 1968. A recording photometer for biological studies. Ecology 49: 161-62.

Bigham, J. T. 1941. Hippelates (eye gnats) investigations in the southeastern states. J. Econ. Ent. 34: 439-44.

Dorner, R. W. \& M. S. Mulla. 1961. Response of the eye gnat Hippelates collusor to light of different wave lengths. Ann. Ent. Soc. Amer. 54: 69-72.

1962. Laboratory study of wind velocity and temperature preference of Hippelates eye gnats. Ann. Ent. Soc. Amer. 55: 36-39.

Dow, R. P. \& V. D. Hines. 1957. Conjunctivitis in southwest Georgia. Pub. Hlth Rept. 72: 441-48.

Dow, R. P. \& G. A. Hutson. 1958. The measurement of adult populations of the eye gnat Hippelates pusio. Ann. Ent. Soc. Amer. 51: 351-60. 
Gerhardt, R. R. \& R. C. Axtell. 1972. Flight of the eye gnat, Hippelates pusio (Diptera: Chloropidae): Effect of temperature, light, moisture and wind velocity. J. Med. Ent. 9: 425-28.

Hummadi, M. K. \& G. R. DeFoliart. 1967. Biology of Hippelates pallipes and $H$. bishoppi (Diptera: Chloropidae) in Wisconsin. J. Med. Ent. 4: 66-70.

Jay, E. G. 1962. Species of Hippelates (Diptera: Chloropidae) gnats collected from mammals. J. Econ. Ent. 55: 1011-12.

Kumm, H. W. 1935. Annual report-Entomological studies made for the Jamaica Yaws Commission during 1934. Rept. Jamaica Yaws Commission for 1934: 19-30.

Kumm, H. W. \& T. B. Turner. 1936. The transmission of yaws from man to rabbits by an insect vector, Hippelates pallipes (Loew). Amer. J. Trop. Med. 16: 245-62.
Roberts, R. H. 1968. A feeding association between Hippelates (Diptera: Chloropidae) and Tabanidae on cattle: its possible role in transmission of anaplasmosis. Mosquito News 28: 236-37.

Sabrosky, C. W. 1951. Nomenclature of the eye gnats (Hippelates spp.). Canad. Ent. 73: 23-27.

Sanders, D. A. 1940. Musca domestica and Hippelates fliesvectors of bovine mastitis. Science 92: 286.

Taplin, D., N. Zaias \& G. Rubell. 1967. Skin infections in a military population. Chap. 1. In: Developments in Industrial Microbiology, Vol. 8. Amer. Inst. Biol. Sci., Washington, D. C. p. 3-12.

Womeldorf, D. J. \& E. W. Mortenson. 1963. Hippelates gnats in central California. Calif. Vector News 10: $57-62$. 